\title{
THE USE OF HYDROGELS TO IMPROVE THE PSYCHOPHYSIOLOGICAL AND PSYCHOMOTOR CONDITION OF MILITARY PERSONNEL CARRYING OUT TASKS UNDER THE CONDITIONS OF HEAT
}

\author{
Anna CZERWIŃSKA, Anna PRZEWODZKA \\ Military Institute of Aviation Medicine, Warsaw, Poland
}

\begin{abstract}
Source of support: The work was carried out within the framework of the development project No. 0042/R/T00/T00/2009/08 "Soldier as a precision weapon - packages and sets: protection against NBC and environmental hazards; nutrition and pharmacotherapy - survival in difficult conditions and optimization of psychophysical performance; medical - biologically active dressings" Task 9: "Improvement of the psychophysical condition of a soldier in hot conditions by the possibility of using a cooling pillow ". The research project was cofinanced by the Ministry of National Defence.
\end{abstract}

Author's address: A. Czerwińska, Military Institute of Aviation Medicine, Krasińskiego 54/56 Street, 01-755 Warsaw, Poland, e-mail: a.czerwinska@wiml.waw.pl

Introduction: The aim of the study was to evaluate the effect of cooling hydrogel on psychophysiological condition, psychomotor efficiency of the organism and subjective thermal sensations and workload in hot conditions.

Methods: The experimental group consisted of 26 healthy men not acclimated to high temperature. The unit test was conducted under simulated high temperature conditions (thermal chamber): $\mathrm{Ta}=35 \pm 1^{\circ} \mathrm{C}, \mathrm{RH}=30 \pm 1 \%, \mathrm{t}=105 \mathrm{~min}$ ) in the environment of which the respondents alternately passed through rest and exercise cycles $(1.5 \mathrm{~W} / \mathrm{kg}) . \ln 40 \mathrm{~min}$ of exposure to the combined heat load conditions (exo and endogenous load conditions) examined a hydrogel filled with active cooling agent $-0.35 \%$ of menthol lactate was applied in the neck and sternum area of the participants. During the experiment, objective physiological indicators were recorded: HR, Tc, Tsk (neck and sternum area) and subjective sensations: assessment of the severity of physical workload (Borg test), state of thermal comfort for the whole body and assessment of thermal sensations in relation to the cooled area of the neck and sternum (Bedford test). Psychomotor efficiency and concentration of attention were assessed on the basis of: the adjective scale of mood UMACL, RW test, the visual-motor tester.

Figures: 12 - References: 19 - Full-text PDF: http://www.pjambp.com • Copyright @ 2016 Polish Aviation Medicine Society, ul. Krasińskiego 54/56, 01-755 Warsaw, license WIML •Indexation: Index Copernicus, Polish Ministry of Science and Higher Education 
Results: In patients using hydrogel favourable physiological changes of physiological parameters were observed, which indicated a reduction of heat load (lower Tsk values in both the neck and sternum area) and reduction of cardiovascular load (heart rate at a relatively constant level). As a result of hydrogel's action, the subjective assessment of thermal comfort, thermal sensations and annoyance of physical workload was also improved, as well as in terms of concentration of attention, visual-motor coordination and emotional state of the examined persons.

Conclusions: The applied hydrogel filled with $0.35 \%$ of menthol lactate effectively improves psychophysiological and psychomotor state of the organism in a state of positive heat load and positively influences the deterioration of subjective thermal sensations.

Keywords: selective body cooling, hydrogel, thermal comfort, thermal sensations

\section{INTRODUCTION}

The conditions of a real flight (environment with combined action of many factors - hypoxia, overstress, vibration or thermal factor) cause that the pilot's organism may be subjected to extreme stress being on the limit of physiological capacity of the organism. Maintaining the optimum ability to perform operator functions and thus maintaining the security of missions in such a specific area as aviation is very difficult and poses no small challenge (especially for personnel who have not passed the acclimatisation/acclimation process). The temperature of the environment in which military personnel are staying, due to the influence it exerts on physiological processes, psychomotor efficiency and the course of cognitive processes, is extremely important for the effective and correct implementation of activities. Conducting tasks in extreme situations and carrying out missions (stabilization or combat) in the hot climate zone exposes the body of a soldier to considerable thermal discomfort resulting from the necessity of performing tasks in conditions of high ambient temperature. The excessive heat load of the body is caused not only by the exposure to the influence of heat, but also by the microclimate of the place of work of various enclosed spaces (e.g. a tank, overheated cockpit during low-altitude flights, in case of an emergency of the systems cooling the pilot cabin, while waiting for take-off). The risk of exceeding the body's physiological tolerance limit to high temperatures also necessitates the use of special clothing (e.g. protective suits, overload protective clothing) and specialised equipment.

The above-mentioned factors may limit the elimination of excessive heat and thus facilitate its accumulation in the organism; what is more, some of the equipment elements may be an additional source of heat. Long-term presence in unfavourable hot conditions may eventually result in disturbances of thermoregulatory mechanisms, which lead to uncontrolled development of hyperthermia as a result of high thermal load, dehydration and physical depletion of the organism. In the state of excessive overheating of the organism, psychophysical efficiency is reduced, which to a large extent depends on the ability of the cardiovascular system, the ability to sweat secretion and the body's individual physical capacity. Increasing the body temperature by $2^{\circ} \mathrm{C}$ above normal body temperature even in people accustomed to hot climate and with high physical capacity significantly increases the physiological cost and represents an additional burden for all organs, especially the heart muscle, cardiovascular system, respiratory system and central nervous system. Excessive increase in internal temperature, skin surface temperature and heart rate and excessive accumulation of heat in the body lead to a decrease in efficiency and performance of tasks. They have a significant influence on the worsening of cognitive and intellectual functions in terms of concentration, division and portability of attention, decision making, vigilance and reflex, as well as visual-motor coordination [6], which translates into an increase in the number of errors made during operator activities, and in aviation even the slightest mistake can lead to a catastrophe. In addition, the long-term influence of high temperature on the organism without proper preparation may result in deterioration of resistance of the system to oxygen deficiency in tissues and intensification of air disease symptoms, as well as 
decrease of resistance to flight factors (especially reduction of acceleration tolerance acting on the pilot organism).

Every human being has innate possibilities for the assessment of microclimatic conditions, including thermal comfort, i.e. the state of satisfaction with the thermal environment surrounding the organism not related to a specific temperature value. The most common indicators of thermal comfort felt by people in different thermal environments and leading different physical activities are their own subjective assessments based on the Bedford scale (the state of thermal comfort for the whole body) and the Borg scale (the degree of annoyance of physical workload). Both subjective indicators of sensations depend on the level of physical activity and the isolation rate of clothing used [16]. Moreover, the state of the organism's satisfaction with the surrounding conditions depends on external physical factors, internal physiological processes (metabolic heat production, skin and body surface and interior temperature) and psychological conditions [7]. Equally, the state of thermal sensations is affected by individual, personal human traits, so that each person perceives the surrounding thermal conditions in a different way.

Depending on the subjective sensations of a given person, the action of a given thermal stimulus causes more or less comfortable feelings. As a result, every flow of signals that reaches the hypothalamus (centre of thermoregulation), depending on the subjective state of the body's thermal state, gives a feeling of comfort or discomfort [5]. Temperature stimuli can be received thanks to the endings of thermosensitive neurons (cold receptors and heat receptors unevenly distributed in all areas of the body), which innervate the internal organs and surface structures such as skin and subcutaneous tissue. The transmission of the nerve impulse takes place with the participation of specialized Transient Receptor Potential (TRP) thermosensitive ion channels, which play a key role in the perception of skin temperature differences $[3,9]$. In particular, two of these channels (TRPM8 and TRPA 1 ) are highly sensitive to low temperatures. Although the role of TRPA1 as a cold sensor is still discussed, it is clear that TRPM8 has an important function in feeling cold, thermoregulation, as well as feeling the pain caused by low temperature stimulus (these properties have been confirmed in studies on the population of mice with a deactivated TRPM8 gene). For TRPM8, in addition to the stimulus of low temperature (less than $27^{\circ} \mathrm{C}$ ), the activators can also be specific chemical compounds that induce the feeling of cold, e.g. Menthol [9]. Temperature changes are only perceived by the nervous system if the ambient thermal conditions differ from the skin surface temperature. As a result, in adverse conditions (too low or too high temperatures) that can damage the body's cells and impair its function, it is possible to activate defensive mechanisms that maintain body temperature within optimal limits for biochemical reactions [9].

The possibility of temperature sensation (thermal sensitivity) is not uniform in all areas of the body and its local variation shows a positive correlation with the number and distribution of surface heat and cold receptors [13]. The head area is characterised by a relatively high thermal sensitivity (it is more sensitive to temperature change) than other parts of the body $[1,5,13]$. Selective head area cooling, probably due to the high concentration of temperature-sensitive nerve endings, effectively modulates many adverse effects of internal temperature rise [11,12]. Therefore, the external interference in the sensation of thermal sensations by selective cooling of the head area both during passive exposure to high temperature $[4,2]$ and during physical activity in hot conditions [11] is of great importance not only for the improvement of the subjective evaluation of thermal comfort, but also for the reduction of the nuisance of physical workload. This is related to a reduction in the level of fatigue experienced due to physical activity and a significant increase in internal temperature [2]. Apart from the fact that selective head area cooling is an important determinant in shaping the perceived thermal comfort, it is also of great importance for physiological reactions, and thus the possibility of effective performance of tasks and proper course of cognitive processes, which deteriorate during heat exposure $[14,15]$. Therefore, reducing the heat load by using selective head region cooling can increase the tolerance to high temperature and have a beneficial effect on the psychomotor efficiency of the body.

The aim of the study was to evaluate the effect of the hydrogel applied on the psychophysical state of the organism, psychomotor efficiency and subjective sensation of thermal comfort and the degree of the nuisance of physical workload in hot conditions $\left(\mathrm{Ta}=35^{\circ} \mathrm{C}\right)$.

\section{MATERIAL AND METHODS}

\section{Group of studied persons}

The experimental group consisted of 26 healthy men (age: $28,3 \pm 7,1$ years; height: 1,71 $\pm 0,07 \mathrm{~m}$; 
body weight: $74,5 \pm 5,0 \mathrm{~kg}$; BMl: $26,5 \pm 3,2 \mathrm{~kg} / \mathrm{m} 2$ ) not acclimated to high temperature. All participants underwent qualification tests, were admitted to the study based on the opinion of the occupational physician. During the day preceding the experiment, they were obligated to maintain a hygienic lifestyle (application of dietary recommendations, not consuming alcohol and intoxicants). Participation in the experiment was confirmed by written agreements of all participants in the trial.

\section{Selection of the method of selective cooling}

The material was selected on the basis of literature review and own experience (not published). This shows that the use of external cooling in the neck area can be sufficient to reduce the heat load. Thus, external intervention, i.e. local action of selective cooling can improve the subjective thermal sensations, the state of thermal comfort and the degree of nuisance of physical workload. The study assumes a hypothesis that the hydrogel used will weaken the negative effects of heat load in terms of psychophysiological and psychomotor efficiency of the organism exposed to the influence of heat.

\section{Hydrogel - method of selective body cooling}

Hydrogel matrix was used in the study as a carrier for the active refrigerant with cooling properties. The specific characteristics of the hydrogel in selecting a selective cooling method are shown in Figure 1.

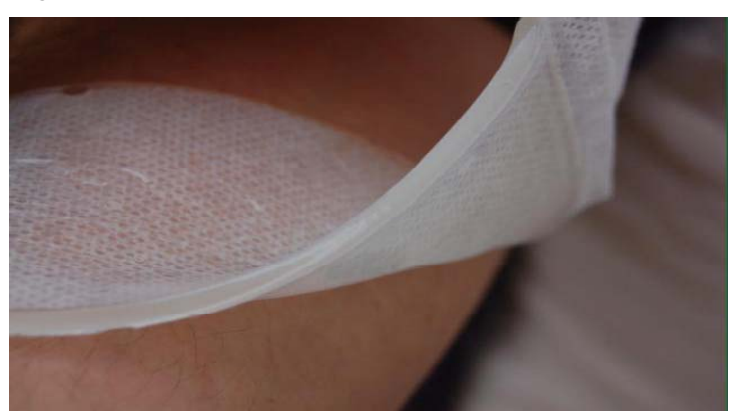

Fig. 1. Actual appearance of the hydrogel and its most important properties: has a large thermal capacity so that it receives warmth well from the body surface and conducts it by evaporation of the external surface; is elastic, plastic and adheres well to selected body surfaces; has a good penetration coefficient; is non-toxic and harmless to the user's source; has high mechanical, thermal and chemical resistance; is not an additional burden, does not adversely affect the mobility comfort.

\section{Structure of hydrogel (fig. 2)}

The hydrogel was based on a technology based on radiation crosslinking of three polymers: polyvinylpyrrolidone (PVP), polyethylene glycol (PEG) and agar. In the process of crosslinking the polymer chains create a three-dimensional spatial network permanently connected thanks to covalent bonds. Hydrogel containing $0.35 \%$ menthol lactate (active agent with cooling properties) has been combined from above with an adhesive fixing material with good adhesion to the healthy skin surface. The transparent lobes of the complex of hydrogel and coolant were stored in a plastic mold $(10 \times 18 \mathrm{~cm})$ and tightly closed and welded foil bag. In this form, the hydrogel (single use) was sterile.

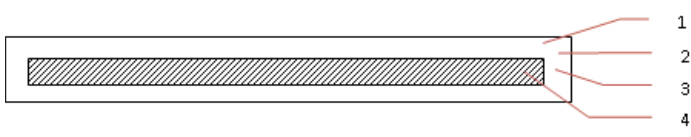

Fig. 2. Diagram of the cooling pack design: 1welded foil bag, 2 - adhesive fixing material, 3 - plastic mold, 4 - hydrogel lobe.

\section{Organisation of tests}

The tests were performed under simulated conditions of the sunny cockpit of the aircraft, in a climatic chamber $\left(\mathrm{Ta}=35 \pm 1^{\circ} \mathrm{C}\right.$ and $\mathrm{RH}=30$ $\pm 1 \%, \mathrm{t}=105 \mathrm{~min}$ ) in the equipment of the Military Institute of Aviation Medicine (WIML). The research project carried out received a positive opinion from the WIML Human Research Ethics Committee. The experiment was carried out in Autumn, at fixed and repeatable intervals. In order to minimize the level of situational stress, all participants were familiarized with the course of the exposure in the climate chamber and its physiological consequences. Additionally, the respondents were acquainted with the principle of operation and course of psychological tests. Each person qualified for the experiment took part in 2 individual tests: series I - control test, without the use of hydrogel, series II - specific test, with the use of hydrogel selectively cooling the area of the neck and sternum (cooling surface $180 \mathrm{~cm} 2$ ). Each unit test was started at the same time in order to minimize differences due to the daily rhythm as much as possible.

\section{Physical characteristics of the unit test}

The unit tests (series I and II) were performed under simulated conditions of the WIML climate chamber with symmetrical temperature distribution. The internal temperature of the chamber shall be maintained at $\mathrm{Ta}=35 \pm 1^{\circ} \mathrm{C}$, relative humidity at $\mathrm{RH}=30 \pm 1 \%$ and the air velocity shall 
not exceed $1 \mathrm{~m} / \mathrm{s}$. The total unit time of exposure on the impact of high temperature was $105 \mathrm{~min}$. In each individual study, recurrent and consistent environmental conditions were maintained.

\section{Running of the specific test procedure (fig. 3 )}

All the participants of the experiment started their test after eating a standardised breakfast, wearing a cotton T-shirt, shorts, socks and sports footwear. After measurements of the initial parameters - core body temperature $(\mathrm{Tc})$, skin surface temperature (Tsk) from the neck and sternum area and psychological tests were carried out (the adjective UMACL mood scale, RW test, visualmotor tester), for 40 mins the tested were seated in the interior of the climate chamber ( $\mathrm{Ta}=35 \pm$ $1^{\circ} \mathrm{C}, \mathrm{RH}=30 \pm 1 \%, \mathrm{t}=105 \mathrm{~min}$ ), being adapted to the high-temperature conditions. After that time has elapsed, participants of the experiment put on hydrogel with an area of $180 \mathrm{~cm} 2$ (in the neck and sternum area). After 5 minutes from the moment of putting the hydrogel on, the participants made a subjective assessment of the state of thermal comfort for the whole body (based on the 7-point Bedford scale). For another 40 minutes, the participants were seated in simulated high temperature conditions. Then they started a 15-minute effort with moderate intensity (cycloergometer, load: $1,5 \mathrm{~W} / \mathrm{kg}$ ). Immediately after the end of the exercise, the participants evaluated the level of nuisance of the workload (based on the 12-point Borg scale). Exposure to the positive heat load was terminated with a resting period of 10 minutes (sitting position). During the last minutes of their stay in the thermal chamber, the subjects made a subjective assessment of the state of thermal comfort in relation to the whole body and the thermal sensations in relation to the cooled areas of the neck and sternum (based on the 7-point Bedford scale). Psycho- logical tests were carried out immediately after the end of the exposure to simulated heat conditions (similarly as in the case of baseline measurements). The control test procedure was the same, the only difference being the lack of hydrogel.

During each individual examination (series I and II) physiological indicators were monitored: core body temperature (Tc), skin temperature (Tsk) in the neck and sternum, and heart rate (HR).

\section{Assessment of objective and subjective psychophysical indicators}

In order to determine the psychophysiological efficiency of the system, measurements were made: 1$)$ core body temperature $\left[{ }^{\circ} \mathrm{C}\right]$ in the outer ear canal; 2) skin temperature in the neck and sternum $\left[{ }^{\circ} \mathrm{C}\right]$; 3) heart rate $[\mathrm{bpm}]$; 4) subjective assessment of the state of thermal comfort for the whole body and the thermal sensations defined for the cooled areas of the neck and sternum - estimated based on the 7 point Bedford scale where 1 - means 'very cold', 7 - means 'very warm'; 5) subjective assessment of the degree of nuisance of physical workload - determined on the basis of the 12-point Borg scale, in which 1 - means 'very light work', 12 - means 'very hard work'.

\section{Assessment of psychomotor fitness and concentration of attention}

Psychological tests were used to assess psychomotor fitness and concentration of attention:

1. Test on the visual-motor tester - assessment of performance: concentration of attention and visual-motor coordination under variable time pressure. At the edge of the tester, the lights were lit sequentially - one in the vertical and one in the horizontal row. The tested person's task was to press the button at the intersection of the coordinates defined by

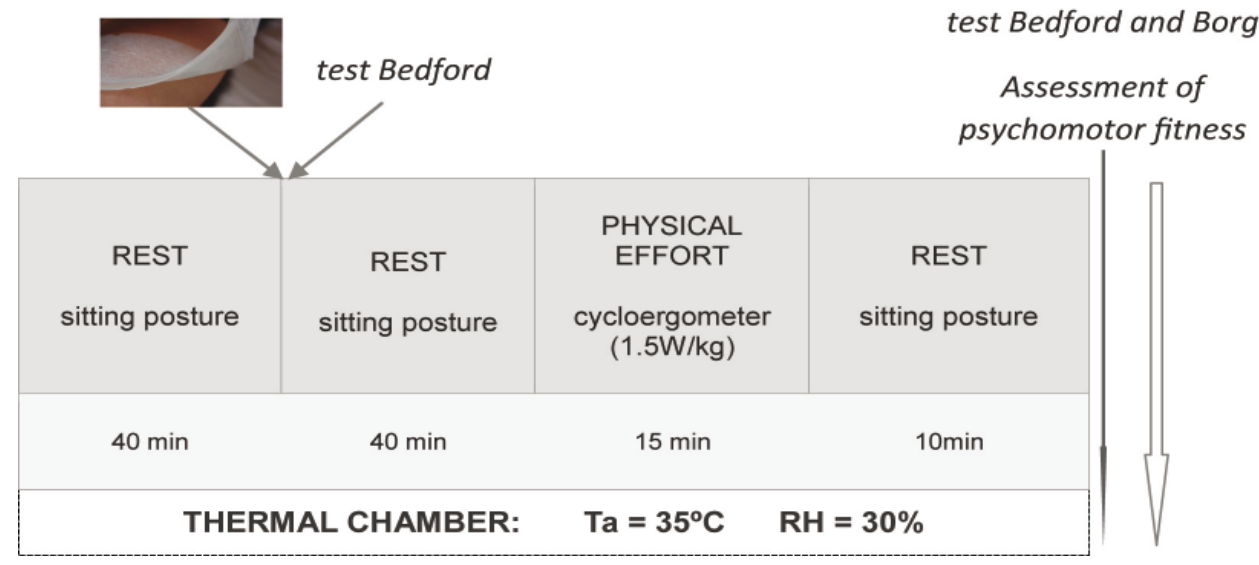

Fig. 3. Progress of the unit examination conducted in simulated heat conditions. 
the luminous points. The test was performed at two rates: the one imposed -70 pulses/min, where the subsequent stimulus appeared independently of the respondent's reaction and at a free rate, in which each stimulus system appeared as a result of the respondent's correct reaction. The result of the test was: reaction time, number of errors committed, average response time (for free rate) and number of received stimuli (for the imposed rate).

2. RW attention test - evaluation of speed and accuracy of operation. Due to the necessity of strong cognitive and executive control, it can be treated as a measure of efficiency of the central executive system. The respondent's task was to assess the position of the white point in relation to the black point and then to check the appropriate box (the questionnaire contained 26 examples). The result of the test was the time of task completion and the number of mistakes made. For the purpose of the conducted research, 10 parallel versions of the test have been prepared.

3. Adjective UMACL Scale - evaluation of the mood understood as an affective experience of moderate duration (at least a few minutes) and not related to the object. The UMACL scale consists of 29 positions in the form of adjectives. The subject's task was to determine, on a 4-degree scale (yes, rather yes, rather no, definitely not) to what an extent each of the adjectives listed in the UMACL scale determined their current mood. Three dimensions of mood were evaluated: energetic excitation $(\mathrm{PE})$, tension excitation (PN) and hedonistic tone (TH).

\section{Statistical analysis}

StatSoft Statistica 6.0 statistical package was used to analyze the results. Variables from the

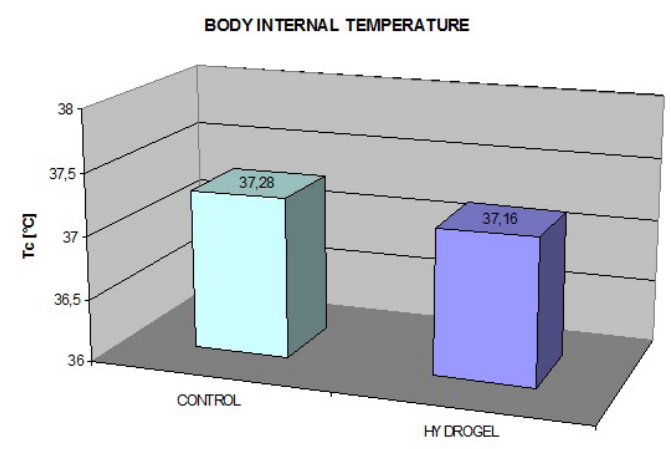

Fig. 4. Core body temperature Tc $\left[{ }^{\circ} \mathrm{C}\right]$ recorded in 105 minutes of the experiment (at the end of exposure to combined positive heat load conditions). control test and hydrogel test with the application of hydrogel selectively cooling limited body areas are described, giving the arithmetic mean and standard deviation $( \pm S D$ ). The significance of the differences in psychophysiological parameters studied under the influence of hydrogel action (assuming normality of their distribution) was assessed using the parametric test t-Student for independent tests. The value $p<0.05$ was assumed as the materiality level.

\section{RESULTS}

In the conducted experiment, in which the subjects were subjected to the influence of the combined effect of positive heat load (endo- and exogenous in nature) in combination with cooling of limited parts of the body (neck, sternum) a positive effect of the method of selective cooling on the psychophysiological, psychomotoric and subjective abilities of the study participants was observed.

\section{Objective physiological indicators}

Core body temperature. As a result of exposure to combined conditions of positive heat load, a slight increase in body temperature (Tc) on average of $0.2^{\circ} \mathrm{C}$ from the baseline (fig. 4) was observed in both the control test and the appropriate hydrogel specific test. Taking into account the temperature values recorded after the end of exposure to simulated heat conditions (105mins of experience) no statistically significant differences were observed between the individual groups (series I and II).

Skin surface temperature. As a result of the application of hydrogel filled with an active cooling agent, lower values of skin surface temperature (Tsk) of cooled body areas were obtained (fig. 5). Those using hydrogel had significantly lower skin temperatures in both the area of the selectively cooled neck area (Tsk $=30.9 \pm$ $2.07^{\circ} \mathrm{C}$ ) and the sternum $\left(\mathrm{Tsk}=31.4 \pm 1.48^{\circ} \mathrm{C}\right)$. The skin surface temperature (in the cooled areas of the body) obtained after application of the hydrogel was significantly lower $(p<0.05)$ in relation to the control group (Tsk of the neck $=33.6 \pm 1.86^{\circ} \mathrm{C}$; Tsk of the sternum $=34.0$ $\left.\pm 1.38^{\circ} \mathrm{C}\right)$. 


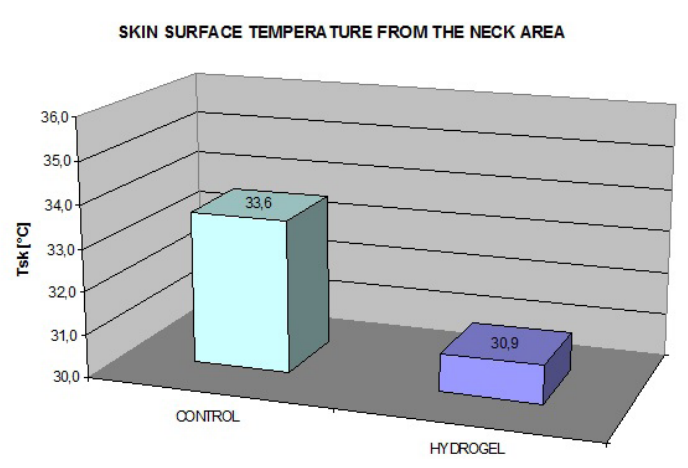

(A)

SKIN SURFACE TEMPERA TURE FROM THE STERNUM AREA

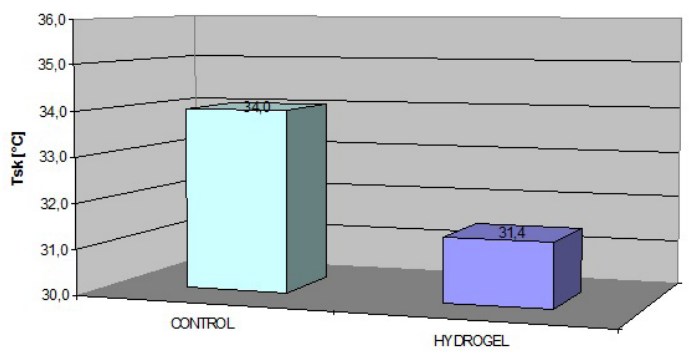

(B)

Fig. 5. Skin surface temperature Tsk $\left[{ }^{\circ} \mathrm{C}\right]$ obtained in the neck area (A) and sternum area (B) recorded in 105 minutes of experiment.

Heart rate. In participants using hydrogel filled with $0.35 \%$ menthol lactate, a lower cardiovascular load ( $\mathrm{HR}=83 \pm 6.19 \mathrm{bpm}$ ) was observed in relation to the values achieved in the control group (HR $=88.4 \pm 11.73 \mathrm{bpm}$ ) (fig. 6). The results obtained within the frames of this parameter indicate that the increase in heart rate is limited and thus they confirm the beneficial effect of hydrogel. The differences within the frames of a given physiological indicator (between the control group and hydrogel users) were statistically significant.

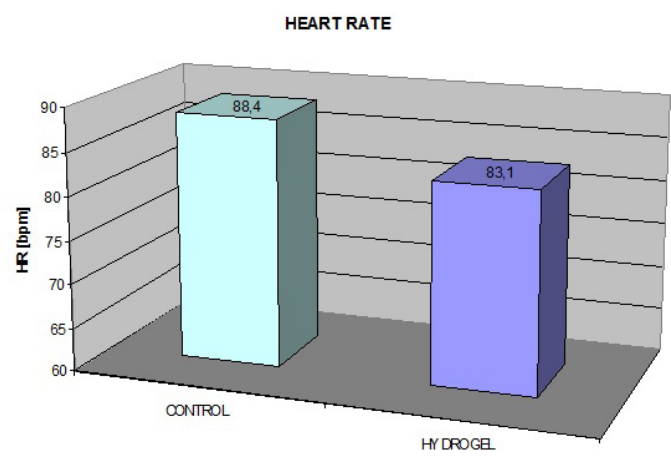

Fig. 6. Heart rate HR [bpm] recorded in 105 minutes of the experiment (at the end of exposure to combined conditions of positive heat load climatic chamber: $\mathrm{Ta}=35 \pm 1^{\circ} \mathrm{C}, \mathrm{RH}=30 \pm 1 \%$ ).

\section{Subjective psychophysiological indicators}

The state of thermal comfort assessed for the whole body (Bedford test). In the study, the influence of the applied hydrogels on the assessment of subjective thermal sensations and perceived thermal comfort was verified based on the 7-point Bedford test. The group of respondents using hydrogel filled with $0.35 \%$ menthol lactate after the end of exposure to heat (105min experience) assessed the whole-body thermal comfort as neutral $(4.3 \pm 1.28)$, at a level close to the level reached in $5 \mathrm{~min}$ of selective cooling $(45 \mathrm{~min}$ of chamber exposure; $3.9 \pm 1.06$ ) (fig. 7A). The comparative analysis did not show any significant differences between subjective assessments made by control group members and hydrogel users.

SUBJECTIVE EVALUA TION OF THERMAL COMFORT IN RELATIONS TO THE ENTIRE BODY

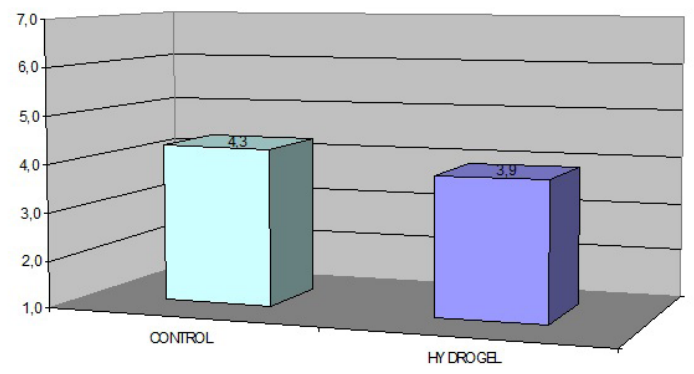

(A)

SUBJEC TIVE EVALUA TION OF THERMAL COMFORT IN RELATIONS TO THE ENTIRE BODY

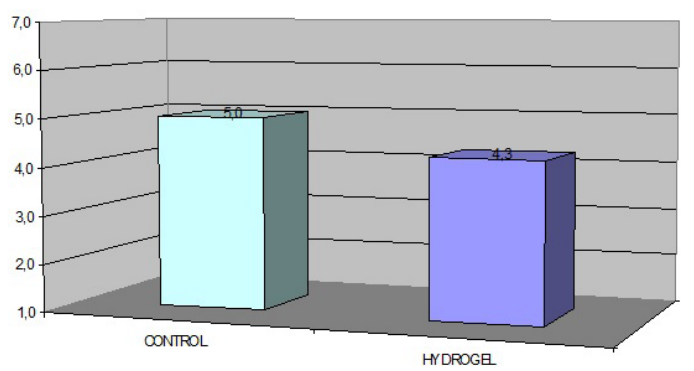

(B)

Fig. 7. Bedford test performed in $45 \mathrm{~min}$ of chamber exposition ( $5 \mathrm{~min}$ after hydrogel insertion) (A) and $105 \mathrm{~min}$ of exposure to positive thermal load (B).

Thermal sensations defined for the cooled body area (Bedford test). In terms of subjectively assessed thermal sensations in relation to the cooled area of the body, those who use hydrogel filled with an active refrigerant were found to experience lower levels of thermal stress in the neck area (heat sensations assessed as "cold"; $2.9 \pm$ 0.99). In the study subjects belonging to the control group who did not use the method of selective 
cooling, in 105 min the thermal sensation experiments evaluated for the neck area were definitely less well received and evaluated as "heat"; 4,8 $\pm 1,092 ; p<0,05$ ) (fig. 8A). A similar trend was observed for the thermal assessment of the cooled area of the sternum. Persons using hydrogel obtained more favourable subjective thermal sensation assessments defined as "cold" $(3,2 \pm 1,39)$ for the cooled area of the sternum. The changes observed in this group of subjects were significantly lower $(p<0.05)$ in comparison with the control group, where thermal sensations determined for the same body area were evaluated at the level of "heat" (4.9 \pm 1.019$)$ (fig. 8B).

SUBJECTIVE EVALUA TION OF THERMAL COMFORT IN RELATIONS TO THE NECK AREA

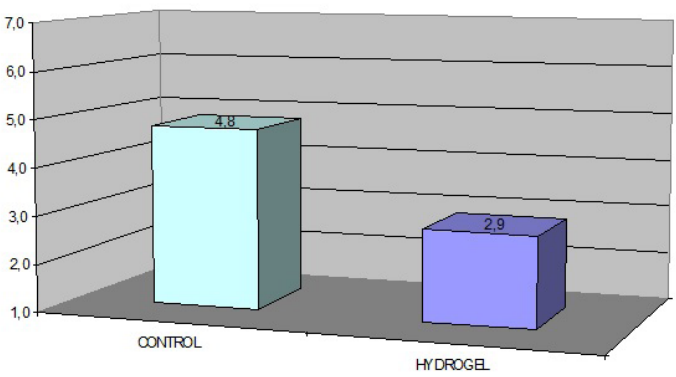

SUBJECTIVE EVALUA TION OF THERMAL COMFORT IN RELATIONS TO THE STERNUM AREA

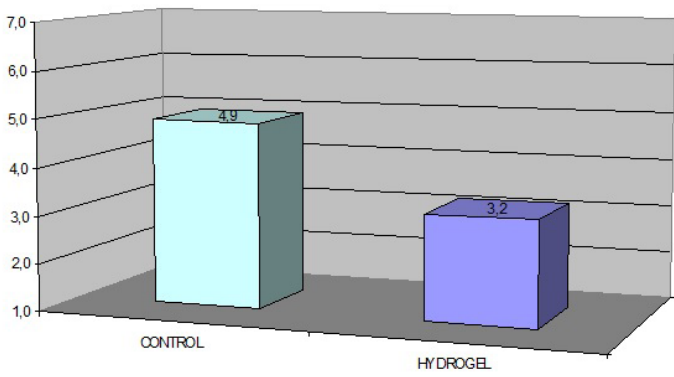

(B)

Fig. 8. Bedford test-assessment of thermal sensations for the cooled neck area $(A)$ and sternum area (B), 105min of exposure to combined positive heat load conditions.

Degree of nuisance in physical workload (Borg test). The analysis of subjective assessments referring to the degree of nuisance of physical workload performed showed more favourable changes in the group of people using hydrogel filled with $0.35 \%$ menthol lactate (work defined as "moderately heavy"; $5.6 \pm 1.77$ ) (fig. 9). In the case of the control group, the estimated values of the analysed parameter remained at a slightly higher level (work assessed as "heavy"; $6.6 \pm 2.45$ ) indicating a higher perceived level of workload. However, the changes obtained in the comparative analysis between the tested hydrogel users and the members of the control group were not statistically significant changes.

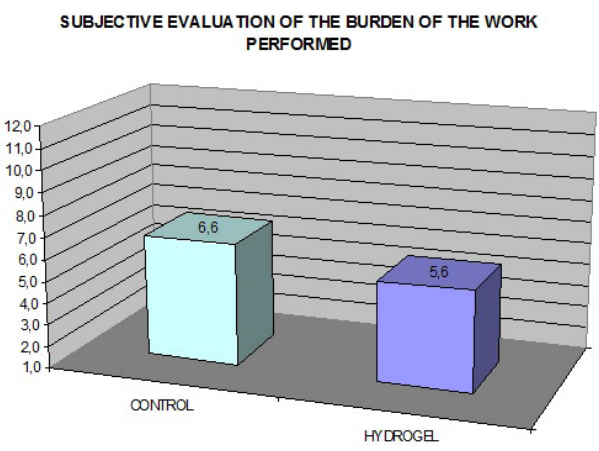

Fig. 9. Borg Test - evaluation of the nuisance of the work performed, 105min of exposure to combined conditions of positive heat load.

\section{Assessment of psychomotor fitness and concentration of attention}

Visual-motor tester. The number of errors (LPB) determined at the free rate (fig. 10B) was the first of the analyzed skills in the visual-motor tester designed to evaluate visual-motor coordination under variable time pressure. In case of this parameter, more favourable effects (less mistakes made) were obtained in the tested hydrogel users (śrLPB = 1.2 \pm 1.94 ), in comparison with the control group (śrLPB $=3.06 \pm 2.31$ ). In terms of the evaluation of the average response time (śrCR) to a single stimulus (at the free rate), a greater reflexion was also demonstrated by the respondents using hydrogel selectively cooling the selected areas of the body (śrCR = 670.00 $\pm 70.68 \mathrm{~ms}$ ) (fig. 10A). In persons belonging to the control group, a longer mean response time was achieved (śrCR $=780.00 \pm$ $127.28 \mathrm{~ms}$ ). The changes of both parameters (LPB, $\mathrm{CR}$ ) between the control group and the group using hydrogel were statistically significant $(p<0.10)$. Another parameter examined on the visual-motor tester was the number of stimuli received (LOB) determined in accordance with the imposed rate. In this case, a minimally more favourable effect was observed in people using hydrogel (śrLOB $=39,80$ $\pm 9,19$ ). The study subjects belonging to the control group achieved slightly worse results (śrLOB $=38,17 \pm 10,78$; fig. 10C). The observed changes were not statistically significant. 


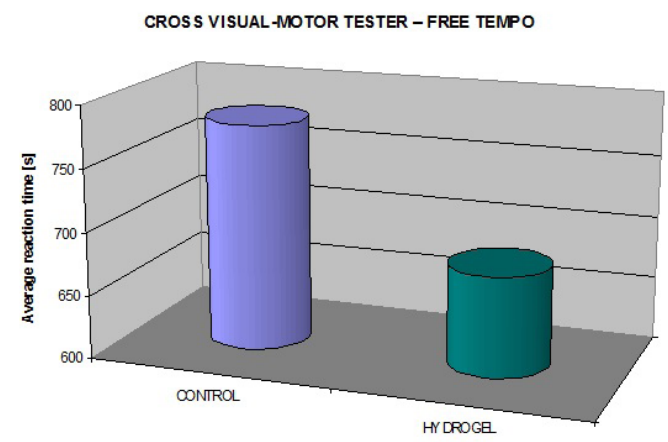

(A)

CROSS VISUAL-MOTOR TESTER - FREE TEMPO

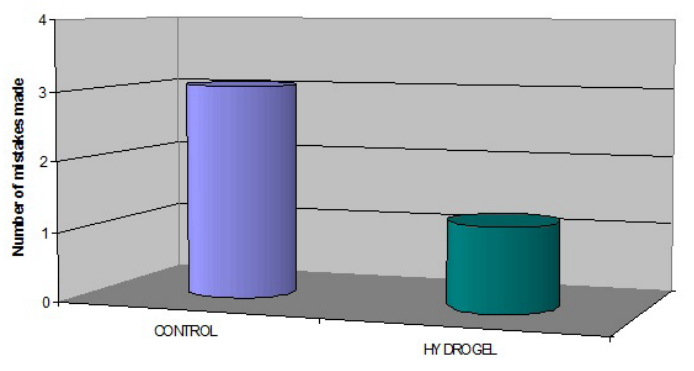

(B)

CROSS VISUAL-MOTOR TESTER - FREE TEMPO

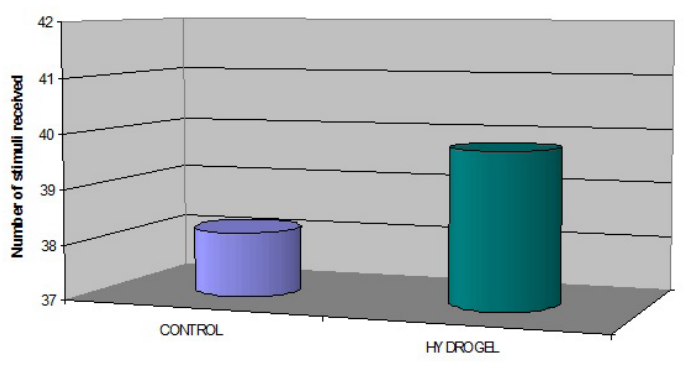

(C)

Fig. 10. Assessment of visual-motor coordination: $(A)$ free rate - mean response time/CR, $(B)$ free rate - number of errors made/LPB, (C) imposed rate - number of received stimuli/ LOB performed immediately after the exposure to simulated heat conditions.

RW test. In the RW attention test used to evaluate the speed and precision of operation, a positive effect of the applied hydrogel was observed, which effectively shortened the time needed to complete the task (śrRW $=18,46 \pm 3,13 s$ ) (fig. 11). Persons belonging to the control group performed the RW test significantly longer (śrRW = $23,70 \pm 8,15 \mathrm{~s})$. Favourable changes obtained after the application of hydrogel filled with $0.35 \%$ menthol lactate compared to the control group were statistically significant changes $(p<0.10)$.

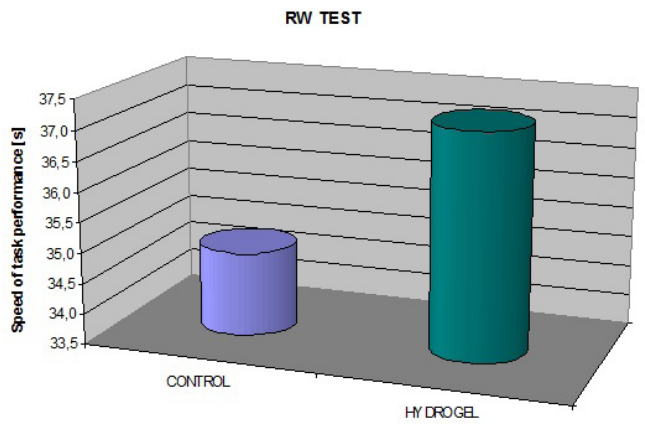

Fig. 11. Assessment of the speed of task performance, carried out immediately after completion of exposure to the conditions of positive thermal load.

UMACL adjective scale. The results of the UMACL questionnaire indicated a positive impact of the selected selective body cooling method (in the neck and sternum area). Effective action was observed on all three correlated mood measures, which were analysed: energetic level $(\mathrm{PE})$, tension level (PN) and hedonistic tone (TH) (śrPE $=35.10 \pm$ 2.56, śrPN $=11.80 \pm 2.44$, śrTH $=37.20 \pm 2.49$ ) (fig. 12 A - C). In the case of the control group no improvement in the perceived mood level was found. Statistical analysis of hedonistic tone scores between hydrogel users and the control group showed a difference in a statistically significant trend level $(p<0.10)$.

UMACL ADJECTIVE SCALE

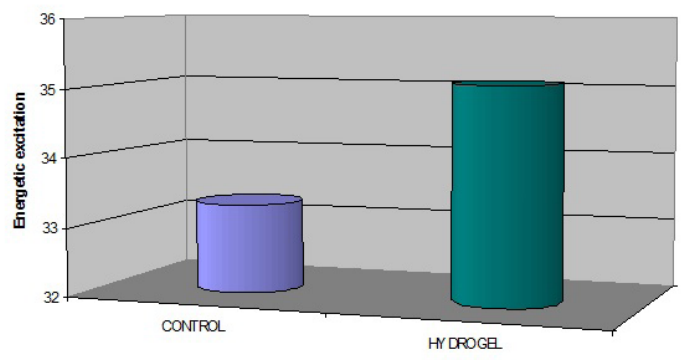

(A)

UMACL ADJECTIVE SCALE

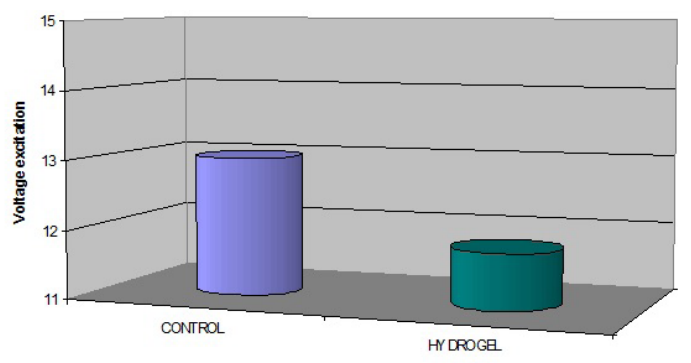

(B) 
UMACL ADJECTIVE SGALE

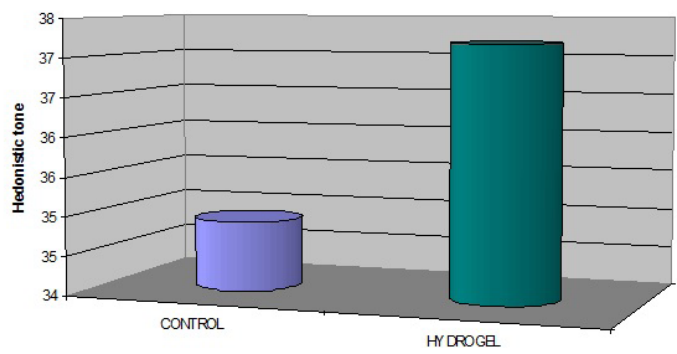

(C)

Fig. 12. Emotional state level determined immediately after exposure to conditions of positive heat load, determined based on the assessment of three mood dimensions: energetic excitation $(A)$, voltage excitation (B), hedonistic tone (C).

\section{DISCUSSION}

Today's missions (both peace and combat ones) often require taking action in extreme thermal conditions of the environment. Reducing the body's tolerance to high temperatures is an important health problem for military personnel working worldwide, especially in the hot climate zone. Long-term exposure to heat (exogenous load) combined with significant strain on the organism resulting from the specificity of the tasks performed (endogenous heat) may adversely affect the body's psychophysiological condition. This is due to the fact that exposure of the organism to specific environmental conditions (with variable amplitude and combined action) significantly increases the risk of disturbance of the thermal balance of the organism, which may ultimately result in exceeding physiological limits and leading, among others, to uncontrolled development of hyperthermia or heat injuries dangerous to the health and life of soldiers. Therefore, in order to reduce excessive thermal load, the methods of selective cooling of the underclothing microclimate are still being improved, among others, with the use of cooled liquids, air or phase-change materials - PCM. In practical use, the improvement of the microclimate around the person wearing special clothing has significant limitations, because in the case of using a liquid or air cooling system, an additional source of energy is most often necessary (often limiting the possibility of free movement). In the case of PCM materials, however, phase change occurs once and the amount of heat absorbed depends on the amount of material used. Therefore, such systems supporting the thermal state of the body in physiological overheating tolerance limits are not always used in specific and difficult conditions of missions, including battlefields. Therefore, given the risks of military personnel being exposed to positive thermal stress, it is necessary to develop a strategy to maintain optimal psychomotor performance and thus to efficiently perform tasks (including airborne tasks) and efficient working time. Such an effective and easy to use method of selective cooling (which does not pose an additional load and does not limit mobility) is essential for the possibility of extending human tolerance to high temperatures, thus reducing the physiological cost of the organism and delaying the development of hyperthermia among crews carrying out military tasks in the hot climate zone or in heat conditions overburdening the organism.

The conducted experiment assessed whether the applied hydrogel filled with an active refrigerant with cooling properties $(0.35 \%$ of menthol lactate) significantly affects the subjective sensations (temperature sensations, thermal comfort, workload) as well as the psychophysiological condition and psychomotoric efficiency of the organism in combined conditions of simulated thermal load (exo- and endogenous). Psychophysiological reactions were assessed on the following monitored during exposure in the climate chamber: 1) objective indicators: core body temperature (Tc), skin surface temperature (Tsk) of the cooled area of the neck and sternum, heart rate (HR) and 2) subjective indicators: assessment of the state of thermal comfort for the whole body and thermal sensations for the cooled areas (based on the Bedford test) and an assessment of the workload (based on the Borg test). The positive effect of the applied method of selective cooling in the form of hydrogel filled with $0.35 \%$ menthol lactate with $180 \mathrm{~cm} 2$ of surface area is confirmed by changes in physiological parameters (Tsk, HR). The results obtained for these indicators clearly indicated the beneficial and effective result of the method of selective cooling of selected body surfaces. A confirmation of hydrogel activity on physiological condition of the body is a significant decrease in skin surface temperature (Tsk) observed both in the cooled area of the neck and the sternum, as well as a decrease in the heart rate (HR) (reduction of cardiovascular load). In relation to the monitored core body temperature (Tc), similar dynamics of changes (gradual value increase) were observed both in the control group and in persons using hydrogel. Differences in the range of this parameter indicate that the hydrogel used to selectively cool the body in the neck and sternum area does not affect the internal temperature 
of the body. These results are consistent with the data obtained by other authors who, as a result of local body cooling combined with physical effort and high temperatures, did not observe any significant changes in internal temperature $[4,11,12]$. The positive effect of the selected cooling method is also indicated by subjective assessments of the state of thermal comfort made after exposure to simulated heat conditions (105mins of experience, Bedford test). In this case, the group of people using hydrogel evaluated the thermal comfort for the whole body at a level close to the level reached in 45 min experience ( $5 \mathrm{~min}$ after selective cooling). In patients not using selective cooling, after the end of the exposure to heat, a deterioration of the perceived thermal state with respect to the whole body was observed (a significant advantageous effect of hydrogel with respect to the control group was achieved). Similar changes were achieved in the subjectively assessed thermal sensations determined with reference to the cooled area of the body. After exposure to a positive thermal load, people using hydrogel similarly felt the thermal sensations for both the cooled neck area and the sternum. Therefore, it can be suggested that the external stimulus in the form of hydrogel cooling the selected areas of the body not only limited the decrease in thermal comfort, but even led to a slight improvement in the thermal state of the body under simulated thermal load conditions. On this basis, it can be concluded that those using such a selective cooling method perceived the ambient conditions as being more thermo-neutral (comfortable) than the control group's members. The obtained results are consistent with the results of research conducted by Arens et al., 2006 [1], Mundel et al., 2006 [12] and Nakamura et al., 2008 [13], in which it was found that cooling of relatively small areas of the body e.g. the area of the head, reduces the feeling of heat and has a beneficial effect on the thermal comfort of the body. Also in the aspect of subjective assessment of the degree of nuisance of the performed work, the lowest (more favourable) assessments were obtained in people using hydrogel filled with an active cooling agent. Tests using selective cooling hydrogel described the physical exercise performed (load of $1.5 \mathrm{~W} / \mathrm{kg}$ ) as "moderately heavy". The level of subjectively perceived workload was lower than in the control conditions, where the experiment participants assessed the physical effort carried out under positive heat load conditions as "quite heavy". In the light of the results obtained, selective cooling of limited areas of the neck and sternum, applied under simulated conditions of positive thermal load, led to a reduc- tion and limitation of the growth of perceived fatigue. Similar observations were made by Armada Silva, 2004 [2], who observed that cooling a limited area of the head may, to some extent, improve the tolerance of moderate intensity physical activity. The assessed state of thermal comfort and the degree of physical work nuisance (improvement of subjective impressions) after the hydrogel application testify to its beneficial and effective impact on the body's psychophysiological condition. Therefore, based on the results related to objective and subjective indicators, it can be assumed that a hydrogel containing $0.35 \%$ menthol lactate reduces, to a large extent, the increase of heat load on the body (including cardiovascular system) and thus reduces the risk of exceeding the limits of physiological capacity of the organism. So far, it has been found that regardless of the internal temperature, skin temperature has a significant influence on the body's thermal sensations and cooling of the head area has a beneficial effect on the subjective assessment of discomfort felt in moderate heat conditions $[1,12]$. The analysis of the results of our research also showed that after the application of hydrogel along with a decrease in the mean temperature of the skin in both the neck area and the sternum as well as a reduction in the heart rate, there was a decrease in the deterioration of the subjective assessment of the state of thermal comfort for the whole body and a decrease in adverse thermal sensations felt in the cooled area of the body.

An important determinant guaranteeing the proper functioning of the organism is maintaining the physiological indicators within the tolerated boundaries, because the physiological condition of the pilot affects the pilot's ability to fly an aircraft, and thus the safety of missions and the life of the operator (or the entire crew). The impairment of thermoregulation mechanisms leads to lower psychomotor and cognitive fitness. Inadequate coordination of the received information (e.g. visual) with executive processes which, due to the specific nature of a pilot's work, occur under time pressure, may contribute to the occurrence of dangerous aviation incidents. Therefore, in the aspect of security of the executed missions, speed and precision (no errors) of the operator's actions is extremely important. Welford [19] demonstrated that at the average excitation level, response time is the shortest and highly dependent on fatigue (especially when performing complex tasks) and the state of tension or excessive relaxation can lead to a decrease in response speed $[8,17,18,19]$. The study we conducted assumed that psychomotor efficiency, attention concentration processes 
and emotional state of the examined persons will change under the influence of an external stimulus in the form of hydrogel selectively cooling the selected areas of the body. In a test conducted on the visual-motor tester, excitation of the psychomotor state (visual and motor coordination and attention concentration) was stimulated by the respondent's reaction to light stimuli successively set at a free and imposed rate (70 imp/min). The analyzed values (mean reaction time and the number of errors evaluated at the free rate) confirmed the positive effect of the hydrogel used on the psychomotor state of the examined persons. Based on the results of a test conducted on the visual-motor tester, it can be suggested that such a selective cooling method reduces the decrease in psychomotor efficiency and thus has a positive effect on the level of perception, data processing speed, visual-motor coordination and the pace of making the right decisions, which are extremely important for the proper operation of the operator. Accuracy and speed of perception have a significant influence on the course of the implemented activities and their safety. These abilities are the basis for good observation (environmental perception) and depend not only on training, experience, mental ability, but also on the ability to focus attention, its ability to shift and divide, as well as clear and fast analytical thinking. It is well known that stressful situations causing emotional disorder are usually accompanied by difficulties in concentration of attention leading to a decrease in the ability to predict dangerous situations, which results in a reduction of the pilot's combat value and increases the probability of making a mistake. In the conducted study, the influence of the applied cooling on the level of attention of concentration under simulated positive heat load conditions was verified on the basis of the RW test. Based on the results obtained, it is possible to suggest a positive effect of the applied method of selective cooling, because people using a hydrogel filled with an active cooling agent completed the task in a shorter time (compared to participants from the control group). The level of excitement was determined on the basis of a three-dimensional well-being model in the form of an adjective mood scale (UMACL). The obtained results included the evaluation of: energetic excitation (PE), which can be defined as energy to act, tension excitation (PN) reflecting anxiety-forming states and hedonistic tone $(\mathrm{TH})$ reflecting subjective pleasure. The high effectiveness of the hydrogel used is proved by positive changes in the three correlated mood measures ( $\mathrm{PE}, \mathrm{PN}, \mathrm{TH})$. As a result of selective cooling, the perceived energy level and hedonistic tone $(\mathrm{TH})$ increased, while the reduction of tension excitation (PN) confirms a decrease in stress and emotional tension. The obtained results are consistent with the assumptions of the UMACL scale, which is based on three dimensions of the emotional state in the examined group of people. The obtained data confirmed a negative correlation of hedonistic tone $(\mathrm{TH})$ with tension excitation (PN) and a positive correlation with energetic excitation (PE) [10], i.e. A high hedonistic tone was accompanied by a rather low tension excitation and moderately high energetic excitation. This emotional state of well-being and good mood was determined in people using selective cooling of the selected body surfaces in the form of hydrogel filled with an active agent in the form of $0.35 \%$ menthol lactate.

Due to the serious threats of military personnel resulting from exposure to positive thermal stress, it is necessary to develop an effective and easily accessible method of cooling the body, which delays the development of hyperthermia and increases the body's tolerance to high temperature. Based on the results of the experiment, it can be suggested that such a potential method of selective cooling is the external action of the cooling stimulus in the form of the hydrogel applied.

\section{CONCLUSIONS}

The obtained results suggest that the hydrogel applied on a limited, small area of the body allows maintaining the body temperature within the physiological range, decreases physiological cost of the organism reducing heart rate and skin surface temperature both within the cooled area of the neck and the sternum. It thus alleviates the undesirable effects of physiological stress while minimizing the susceptibility to heat injuries.

By selective cooling of the body under simulated thermal load conditions, the temperature sensation has been improved. In the conditions of a positive heat load, the method of selective cooling favourably influences the improvement of subjective indicators: assessment of the state of thermal comfort for the whole body and the thermal sensations related to the selectively cooled areas of the body (neck and sternum area). A higher level of thermal comfort is a consequence of local thermal sensation (in the neck/sternum area). Therefore, it can be concluded that this type of selective cooling is an appropriate protection against thermal discomfort, often limiting the efficient and safe execution of activities. Changes re- 
lating to subjective workload indices confirm that hydrogel, through local action, also has a positive effect on improving the subjective assessment of the workload and thus reducing the level of fatigue build-up. The applied method of selective cooling, in the form of hydrogel filled with $0.35 \%$ menthol lactate, positively influences the emotional state of the organism, psychomotor abilities (reducing the number of mistakes, shortening the average reaction time and increasing the number of stimuli received) and prevents the decrease of attention concentration.

\section{AUTHORS' DECLARATION:}

Study Design: Anna Czerwińska, Anna Przewodzka; Data Collection: Anna Czerwińska, Anna Przewodzka; Manuscript Preparation: Anna Czerwińska, Anna Przewodzka; Funds Collection: Anna Czerwińska, Anna Przewodzka. The Authors declare that there is no conflict of interest.

\section{REFERENCES}

1. Arens, E., Zhang, H., Huizenga, C. Partial-and whole-body thermal sensation and comfort, Part II: non-uniform environmental conditions. J. Therm. Biol. 2006; 31 (1-2): 60-66.

2. Armada-da-Silva, P.A.S., Woods, J., Jones, D.A. The effect of passive heating and face cooling on perceived exertion during exercise in the heat. Eur. J. Appl. Physiol. 2004; 91 (5-6): 563-571.

3. Bandell, M., Story, M., Hwang, S.W., Viswanath, V., Eid, S.R., Petrus, M. J., Earley, T. J., Patapoutian A. Noxious cold ion channel TRPA1 is activated by pungent compounds and bradykinin. Neuron 2004; 41 (6), 849-857.

4. Brisson, G.R., Peronnet, F., Perrault, H., Boisvert, P., Massicotte, D., Gareau, R. Prolactinotrophic effect of endogenousand exogenous heat loads in human male adults. J. Appl. Physiol. 1991; 70 (3): 1351-1355.

5. Cotter, J.D., Zeluca, A., Keizer, E., Taylor N.A.S. (2010). The role of local skin temperature in determining the perception of local and whole-body thermal stateJ. Athl. Train. 2010; 45 (2): 107-116.

6. Faervik, H., Reinersten, R.E. Effect of wearing aircrew protective clothing on physiological and cognitive responses under various ambient conditions. Ergonomics 2003; 8 (46): 780-799.

7. Frank, S.M., Raja, S.N., Bulcao, C.F., Goldstein, D.S. Relative contribution of core and cutaneous temperatures to thermal comfort and autonomic responses in humans. J. Appl. Physiol. 1999; 86 (5): 1588-1593.

8. Killgore, W.D.S., Balkin, T.J., Wesensten, N.J. Impaired decision-making following 49 hours of sleep deprivation. J. Sleep Res. 2006; 15 (1): 7-13.

9. Man-Kyo, Ch., Caterina, M.J. TRP, Channel Knockout Mice Lose Their Cool. Neuron 2007; 54 (3): 345-347.

10. Matthews, G., Chamberlain, A.G., Jones, D.M. Adaptacja. In. Goryńska E., ed. UMACL - Przymiotnikowa Skala Nastroju. Warszawa: Pracownia Testów Psychologicznych Polskiego Towarzystwa Psychologicznego 2005.

11. Mündel, T., Hooper, P.L, Bunn, S.J., Jones, D.A. The effects of face-cooling on the perception of exertion and neuroendocrine response to hyperthermic exerciseJ. Physiol. 2005; 565 P: C31.

12. Mündel, T., Hooper, P.L., Bunn, S.J. The effects of face cooling on the prolactin response and subjective comfort during moderate passive heating in humans. Exp. Physiol. 2006; 91 (6): 1007-1014.

13. Nakamura, N., Yoda, T., Crawshaw, L., Yasuhara, S., Saito, Y., Kasuga, M., Nagashima, K., Kanosue, K. Regional differences in temperature sensation and thermal comfort in humans. J. Appl. Physiol. 2008; 105 (6): 1897-1906.

14. Nunneley, S.A., Reader, D.C., Maldonado, R.J. Head-temperature effects on physiology, comfort, and performance during hyperthermia. Aviat. Space Environ. Med. 1982; 53 (7): 623-628.

15. Nunneley, S.A., Troutman, S.J., Webb, P. Head cooling in work and heat stress. Aerosp. Med. 1971; 42 (1): 64-68.

16. PN-EN ISO 7730:2006 Ergonomia środowiska termicznego- Analityczne wyznaczanie i interpretacja komfortu termicznego z zastosowaniem obliczania wskaźników PMV i PPD oraz kryteriów lokalnego komfortu termicznego (oryg.) 
17. Ramsey, C.S., Werchan, P.M., Isdahl, W.M., Fischer, J., Gibbons, I.A. Acceleration tolerance at night with acute fatigue and stimulants. Aviat. Space Environ. Med. 2008; 79 (8): 769-773.

18. Thomas, M., Sing, H., Belenky, G.., Holcomb, H., Mayberg, H., Dannals, R (2000). Neural basis of alertness and cognitive performance impairments during sleepiness. I. Effects of $24 \mathrm{~h}$ of sleep deprivation on waking human regional brain activity. J. Sleep Res. 2000; 9 (4): 335-352.

19. Welford, A.T. Choice reaction time: Basic concepts. In: Reaction Times. Welford A.T., ed. New York: Academic Press; 1980: 73-78.

\section{ACKNOWLEDGEMENTS}

The views, opinions, and findings contained in this article are our own and should not be construed as an official Polish Air Force position, policy, or decision, unless so designated by other official documentation.

Cite this article as: Czerwińska A, Przewodzka A. The Use Of Hydrogels To Improve The Psychophysiological And Psychomotor Condition Of Military Personnel Carrying Out Tasks Under The Conditions Of Heat. Pol J Aviat Med Bioeng Psychol 2016; 22(4): 13-26. DOI: $10.13174 /$ pjambp.23.02.2018.02 